\title{
Research on Features and Mechanisms of Labor Mobilization under the Background of New Urbanization in China
}

\author{
Xiuli Xiang \\ Zhongnan University of Economics and Law, Wuhan, 430073, China
}

Keywords: Labor mobilization, Labor flow, New urbanization

\begin{abstract}
The core of the new urbanization is people. The new urbanization should be people-oriented and meet the needs of all aspects of the rural labor force. Under the background of new urbanization, the labor force of China has been transferred on a large scale. The paper analyses the features and mechanisms of labor mobilization under the background of new urbanization in China and provides corresponding suggestions, including safeguard legitimate rights, improving employment environment and reducing flow blindness of rural migrant workers to provide some references for the relevant researchers.
\end{abstract}

\section{Introduction}

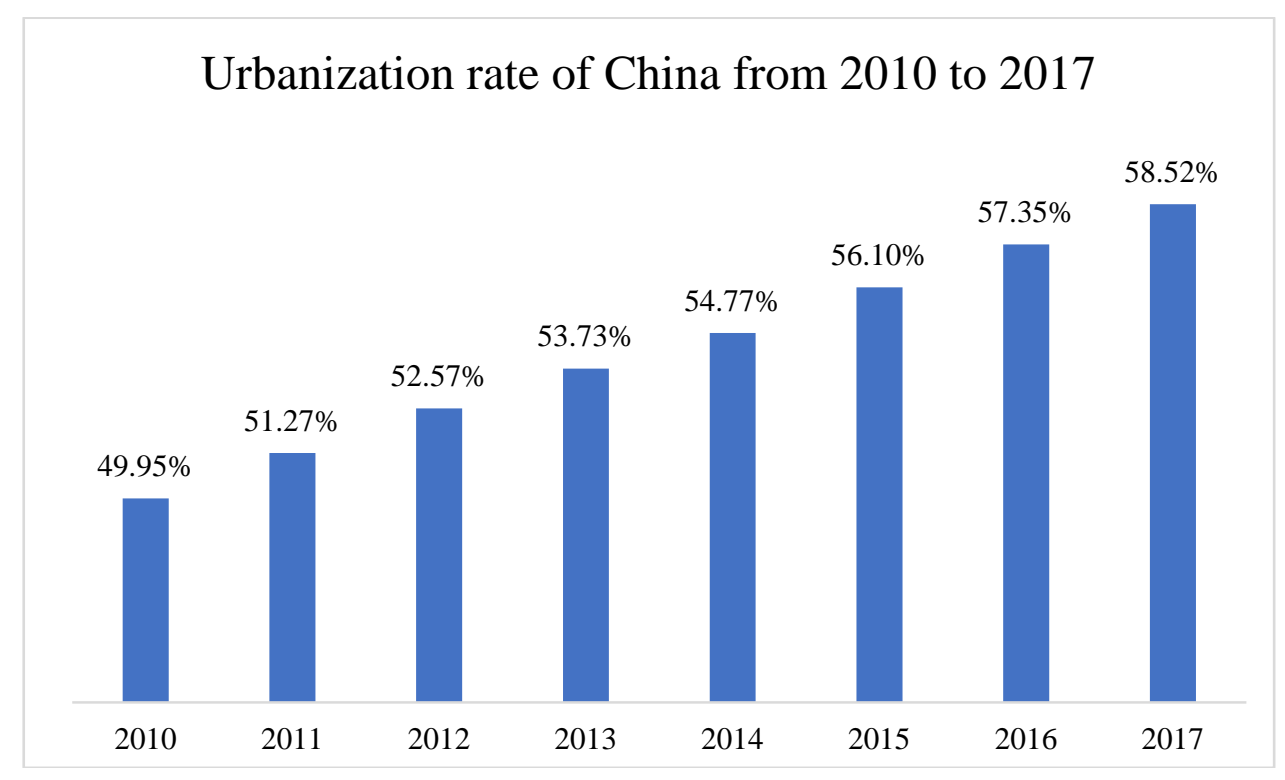

Figure 1. Urbanization rate of China from 2010 to 2017

Urbanization is the process of the transformation of the basic human way of living, which leads to the continuous accumulation of rural residents and the formation of residential quarters. The essence of urbanization is the people, is one of the core of urbanization, namely the peasants to the public, is that the rural residents to really enter the city, so that their life style and behavior have a comprehensive change, their economic ability can be enhanced to improve the efficiency of the whole social economy, the creation of social economy prosperity. With the continuous improvement of urbanization rate, many rural surplus labor force and population will be transferred to cities every year, which will bring huge increase in investment and rapid increase in consumption, and will also provide multi-level human resources for urban development. According to the state statistics, the rate of urbanization is increased by one percentage point, which corresponds to the tens of millions of people and the investment and consumption of trillions of yuan. As far as consumption is concerned, the rate of urbanization is increased by one percentage point per year, and about 10000000 farmers can enter the city. It is worth noting that urbanization is not only the simple transfer of rural population into urban population, but in the trend of the industrial structure optimization, lead to changes in spatial structure and social structure and the evolution of resource allocation, so that 
farmers really into the city in economic life. The "new" of new urbanization refers to renewal of concept, system innovation, technological innovation and cultural renovation. It is the ecological development process of new industrialization, regional urbanization, social informatization and agricultural modernization. Urbanization is the biggest source of structural adjustment and domestic demand in our country, and it is the key point to promote the steady and fast development of economy. In this paper, the urbanization rate of China from 2010 to 2017 is calculated, as shown in the figure.1.

\section{Features of Labor Mobilization under the Background of New Urbanization in China}

In recent years, the labor force has shown more and more serious backflow in the more developed cities. The hollowing in rural areas shows the characteristics of outer space. Some scholars have done some research on the return of the domestic labor force. In order to study the characteristics of Anhui's population flow, Xie Xin has the following characteristics: the proportion of the population flowing to the outside of the province has begun to decline, and the time of outgoing time is mainly in the short term, and the distribution is more concentrated. Two provinces in Anhui and Sichuan found that men outgoing women were higher than women, married people tended to be more mobile than unmarried persons, and the proportion of returning was higher. The reflux population in Guangdong Province found that the reflux is mainly young and young, the male labor force is more likely to return, and the return time of the female labor force is earlier. The academic circles put forward two kinds of hypotheses: the theory of failure and the theory of success. Some scholars think that migrant workers are too low in the city because of their low acceptance or comprehensive consideration of the utility that the city brings to them. Their income level is relatively low, and their social integration is relatively low in migrant workers' cities. Another part of scholars believe that migrant workers have certain technological and social capabilities after entering the city, so they feel a sense of success. They think that returning business or returning business can bring more utility, so success factors lead to migrant workers returning. The return of migrant workers is positively related to the level of education, and the higher the level of education, the easier it is to return. In addition to the migrant workers, the high knowledge and skilled talents returning to the small and medium-sized cities are also increasing quietly. In general, labor migration and mobility are affected by economic, policy and social environment factors. In the new stage, the labor force has made new decisions about whether to migrate or not. The decision has made a comprehensive analysis of factors other than income. Instead of just pursuing an economic benefit at the initial stage of labor mobility, they are more consistent with rational people's standards when making decisions.

\section{Mechanisms of Labor Mobilization under the Background of New Urbanization in China}

The new urbanization accelerates the transfer of rural surplus labor force, the rural surplus labor force is generally transferred to the eastern developed area engaged in clothing, textile, electronics, chemical and other industries, those engaged in high density and high strength work, due to limited conditions, their relatively simple living environment, there are a lot of surplus labor in operation companies have no medical insurance, life difficult. The general transfer of rural surplus labor to the city most of young labor force, because the land and homeless and they tend to land management and management of children to the elderly, if the spring harvest season, the home is busy, they then go back to farming, leisure and migrant workers commute to the city, rural. A few years, more and more money accumulated, some people buy a house, in the familiar city to settle down, but they often feel difficult to live in a big city, and most people due to various reasons such as family, or choose to stay in the rural life, from the emotion is not willing to leave their generation the land and rural life. The new urbanization process, rural surplus labor force of choice for many migrant workers, because of their level of scientific and cultural knowledge is limited, unable to engage in sophisticated operations, most them are willing to choose to work South economically developed first-tier cities in the factory. In such areas, the general traffic conditions are convenient. If there are serious problems encountered at home during work, they can return to their homes in time and deal with contingencies. Moreover, in such cities, workers usually work in textile and electronic factories. The conditions are rather hard, 
while the labor intensity is large, but the remuneration for labor is generally large. So, a lot of rural surplus labor is willing to pay a lot of hard work and make more money to get rid of poverty and become rich as soon as possible.

\section{Policy Suggestions of Labor Mobilization under the Background of New Urbanization in China}

\subsection{Safeguard Legitimate Rights of Rural Migrant Workers}

Currently, the basic rights and interests of migrant workers cannot be fully guaranteed, there is a lack of government management and the lack of legal system. The weakness is embodied in many aspects, such as economic interests, legal rights and interests, political rights and social security. In the long run, we must eliminate the system of inequality of rights between urban and rural residents attached to hukou, and protect citizens' freedom of migration, freedom of residence and freedom to choose jobs. It is necessary to reduce the household registration threshold and relax the household conditions at different levels. The household registration of small cities and small towns should be all open. In large and medium-sized cities, those who have legitimate residence, stable occupation and source of life can settle in the city, register their accounts, and enjoy the rights and obligations of residents according to law. In megacities, residence permit system can be implemented. The land system is closely related to the transfer of rural surplus labor. At present, it is necessary to promote the transfer of rural labor force in the central and western regions, and appropriately relax the macro control of land according to the relatively rich land resources to adapt to the gradient transfer of industries and speed up the economic development in the central and western regions. In the long run, the urban and rural workers should establish a unified social security system. Soon, the social security network of multi-level, low level and wide coverage should be set up in accordance with the low wages of migrant workers and the different situation of the floating population. The threshold of reducing the participation of migrant workers in social security. The payment base and payment age should be adapted to their real wages and share with their businesses in proportion, so that more migrant workers can get the pension when they are old. It allows enterprises to pay pension insurance for rural migrant workers in rural areas, and migrant workers can participate in the local social security department to participate in insurance and return. To establish a convenient and reasonable inter provincial transfer mechanism for migrant workers' endowment insurance, no matter where they move to, they can pay old-age insurance by card, and receive social endowment insurance by card.

\subsection{Improve Employment Environment of Rural Migrant Workers}

At present, many towns are still implementing various explicit or implicit policies and measures to restrict migrant workers to engage in service industry, which is not conducive to the current expansion of rural labor force employment, but also to the second generation of migrant workers who are unwilling to return home for employment, which is affecting the social stability of cities and towns. To this end, we should further clean up all kinds of policies to restrain migrant workers in the service industry. From the two perspectives of the government and migrant workers to carry out research, to find out the various policies to engage in the service industry and migrant workers with specific measures, especially the provisions of various discriminatory barriers and management fees, the phasing out of restrictive measures for the migrant workers, relief management fees, reduce the cost of migrant workers in the service industry. Two we should strengthen the skills training of migrant workers in the new service industry. At present, the migrant workers in the city, especially the second generation of migrant workers, are not satisfied with the industries such as poor environment, energy consumption, low skill and so on. However, many areas of migrant workers training often focus on skills training in industry, construction industry and traditional service industry, and the support for migrant workers in emerging services is not enough. If the migrant workers and their family members move to the input place for a long time, social security services such as pension, medical care and employment are provided by the local governments. The central government will export the social security subsidy funds for migrant workers to the input account. In 
addition, we can explore the establishment of a long-term rural migrant workers to complete the transfer of land, and part of the transfer of funds into the central social security subsidy income category. Therefore, to focus on domestic service industry, computer services, warehousing industry, sports industry, entertainment industry, health industry and other emerging service industries, strengthen the training of migrant workers the coupon payment subsidies, the implementation of technical grade qualification, migrant workers to guide higher skills to master the skills of emerging service industry, the formation of long-term mechanism to increase farmers' income.

\subsection{Reduce Flow Blindness of Rural Migrant Workers}

For the government, more information should be provided to the transfer and flow of the labor force and to guide the flow of labor to the place where demand is exuberant. In addition, workers must invest in human capital to make workers more specialized and professionalized. In the labor market, they can give full play to their abilities and maximize their utility while contributing to the development of social economy. Strengthen the construction of rural education base, including the teaching practice farm, private farm, enterprise and so on. The way of education can be diversified. Government agencies and agricultural organizations take the lead in sponsoring the whole society. We should take all the schools into consideration, undertake apprenticeship and adult education, and their funds are raised by the government, sponsors and trainees. The government should give strong support in rural occupation education, to ensure the financial funds is growing, to the occupation of rural adult school is equipped with advanced experimental equipment, construction meet the teaching requirements of the practice base, the construction of experimental equipment and practice base has advanced and demonstration in technology and production management, the adult occupation school building has become a multifunctional comprehensive education and training base, technology introduction, demonstration and production services, so as to enhance the school's teaching ability and self-developing ability, create conditions for rural surplus labor force to master solid professional knowledge and practical skills. Through the government's input. In addition, the government can also supply the financial funds to farmers through training vouchers or lower fees to reduce the economic burden of training for farmers. Farmer training is a long-term, systematic and arduous project. To comprehensively improve the quality and skills of rural population, we must carry out it in an enduring and lasting way, to achieve the desired goal.

\section{References}

[1] Cao Jianyun. Study on the Relation Among Labor Flow, Concentration and Improvement of Human Capital [J]. Journal of South China University of Technology (Social Science Edition), 2016, 18(5): 36-42.

[2] Zheng Chunling, Huang Ning. Study on Accounting Method for Transaction Prices in Flow of Excellent Human Resources in Internal Labor Market [J]. Coal Economic Research, 2015, 35(5): 57-60+79.

[3] Sha Yong, Lao Xin. The Labor Heterogeneity, the Flow Direction and the Paradox of Gap between Urban and Rural Areas [J]. Population \& Economics, 2015(2): 60-67.

[4] Zhu Yanliang, Wan Yong. Mechanism Analysis of Impact of Labor Flow on Economic Agglomeration [J]. Finance \& Economics, 2015(4): 68-80. 